\title{
O discurso acadêmico sobre o professor na era digital
}

\author{
The academic discourse about the teacher in the \\ digital age
}

Eliana Maria Severino Donaio Ruiz

Universidade Estadual de Londrina (UEL), Londrina, Paraná, Brasil.

elianaruiz@uel.br

Resumo: Tomando como aporte teórico a Análise Discurso de tradição francobrasileira, em uma perspectiva arqueogenealógica foucaultiana, e as contribuições dos Estudos Culturais, esta pesquisa pretende discutir as representações acerca do professor contemporâneo, num contexto fortemente marcado pelas tecnologias digitais de informação e comunicação, em trabalhos acadêmicos em língua portuguesa publicados recentemente. A leitura revelou que está em curso, no campo educacional, uma vontade de verdade que relaciona educação e novas tecnologias, sendo enunciada por especialistas pesquisadores referendados pela sociedade; que tal vontade de verdade constitui uma prática contemporânea de subjetivação do professor; e que essa ordem do discurso pode ser encapsulada por quatro enunciados básicos tradutores dos sentidos que emergem dos excertos selecionados. Intenta-se, assim, uma governamentalidade, um campo estratégico de relações de poder que configura um processo atual de fabricação de uma nova identidade para o sujeito professor atuar na sociedade tecnológica regida pelas relações de mercado e pela lógica neoliberal de governo.

Palavras-chave: professor; tecnologias digitais; discurso acadêmico; representações; governamentalidade.

Abstract: Taking as theoretical support the Discourse Analysis of FrenchBrazilian tradition, in a Foucauldian arqueogenealogic perspective, this research aims to discuss the representations about the contemporary teacher in a context strongly marked by digital information and communication 
technologies in academic papers recently published in Portuguese. The reading revealed that is underway in the educational field a will to truth that relates education and new technologies, being enunciated by expert researchers endorsed by society; that this will to truth is a contemporary practice of teacher's subjectivation; and that this order of discourse can be encapsulated by four basic statements translators of the meanings that emerge from selected clippings. Thus it intends to pursue a governamentality, a strategic field of power relations that sets a current construction of a new identity for the teacher as subject acting in a technological society governed by market relations and the neoliberal logic of government.

Keywords: teacher; digital technologies, academic discourse, representations, governmentality.

Recebido em: 24 de fevereiro de 2015.

Aprovado em: 12 de junho de 2015.

"A globalização envolve uma integração entre fatores econômicos e culturais, causando mudanças nos padrões de produção e consumo, as quais, por sua vez, produzem identidades novas e globalizadas." (WOODWARD, 2009, p. 20).

\section{Palavras iniciais}

Adotando o conceito de paradigma tecnológico e indicando o que chama de penetrabilidade dos efeitos das novas tecnologias como uma de suas características, Castells já anunciava, há mais de uma década: "[c]omo a informação é uma parte integral de toda atividade humana, todos os processos de nossa existência individual e coletiva são diretamente moldados (embora, com certeza, não determinados) pelo novo meio tecnológico" (CASTELLS, 1999, p. 108). Disso advém que as mudanças pelas quais passam os sujeitos e a sociedade no momento globalizado e tecnológico que estamos vivendo têm levado os estudiosos a proporem análises sob os mais variados pontos de vista. Entre essas 
reflexões, têm tido lugar de destaque questões referentes ao papel da escola no mundo contemporâneo. De par com as preocupações voltadas à formação do educando, insere-se também na pauta das discussões a questão de se (re)pensar a função docente num contexto tão específico como esse, de transição de paradigmas.

$\mathrm{Na}$ esteira de tais discussões, este trabalho procura investigar, sob o aporte teórico da Análise de Discurso de tradição franco-brasileira, em uma perspectiva arqueogenealógica foucaultiana, as representações que se tem, no contexto acadêmico da atualidade, acerca desse sujeito da educação, o professor, numa conjuntura sócio-político-econômica altamente marcada pela presença das tecnologias digitais de informação e comunicação. Afinal, que imagem de professor os especialistas constroem quando falam sobre atuação docente nos dias de hoje?

Para esta pesquisa, tomamos como objeto de análise discursiva textos acadêmicos atuais, da área da educação, publicados nos últimos cinco anos, em que os termos "professor" e "tecnologia" figuram no título e / ou no resumo do trabalho. O levantamento consistiu numa busca, no site de periódicos da CAPES, por meio das palavras-chave "professor e tecnologias digitais" e "professor e novas tecnologias". Dada a restrição de espaço estabelecida para a presente publicação, deixamos de lado teses e dissertações, além de artigos publicados anteriormente a 2010. Por essa razão, buscamos também artigos no Google, por meio da palavra-chave "professor e novas tecnologias". Nesse levantamento, chegamos a um total de quinze artigos em língua portuguesa, publicados entre 2010 e 2013 , em revistas especializadas de educação ou multidisciplinares, sendo que, para este trabalho, visitamos excertos de onze deles, a saber: ${ }^{2}$

- Marchiori e Melo e Melo (2011) - professores de Fonoaudiologia - UNOPAR, PR;

- Garcia et al. (2011) - doutores em Educação - UNICAMP,

\footnotetext{
${ }^{1}$ A coleta se deu no segundo semestre de 2014 e se caracterizou por uma escolha aleatória das áreas de conhecimento e da região geográfica a que pertencem os autores investigados e suas respectivas instituições (de formação ou de atuação).

${ }^{2}$ Incluímos, na listagem por data ascendente, a área de formação dos autores e suas respectivas afiliações.
} 
SP;

- Zuin e Zuin (2011) - pós-doutora em Física / pós-doutor em Filosofia da Educação - UFSCar, SP;

- Silva (2011) - doutor em Letras - UFRRJ, RJ;

- Alda (2012) - mestranda em Linguística Aplicada - UCPel, RS;

- Molin e Raabe (2012) - professores de Educação e Computação Aplicada - Universidade do Vale do Itajaí, SC;

- Vieira (2012) - professor de História - Centro Universitário de Maringá, PR;

- Oliveira (2012) - doutora em Educação - FCT-Unesp, SP;

- Dias (2012) - pós-doutora em Linguística Aplicada - PUCSP, SP;

- Soares-Leite e Nascimento-Ribeiro (2012) - Secretaria de Educação do Governo de Estado do Ceará, CE;

- Arruda (2013) - historiador e doutor em Educação FAE/UFMG, MG; e

- Moura e Brandão (2013) - professores de Educação - FAE Faculdade Anglicana de Erechim, PR.

\section{Uma palavra sobre tecnologia, sociedade e educação}

É em estreita relação com as determinações sociais, políticas, econômicas e culturais que o desenvolvimento da ciência e da tecnologia devem ser entendidos. Trata-se do esforço humano em criar instrumentos que superem as dificuldades das barreiras naturais e aperfeiçoá-los, no decorrer do tempo, para atender a necessidades da sociedade humana.

Foi na Grécia, entre os séculos 6 e 4 a.C., esclarece-nos Pinto (2004), que "Platão conceituou o termo técnica, dando-lhe o significado de uma realização material e concreta; Aristóteles não foi muito além dessa conceituação, pois, entendia a techné como um conhecimento prático que objetiva um fim concreto" (PINTO, 2004, p. 3). Já o termo tecnologia, por ter tido seu significado alargado, com enfoques visando a diferentes finalidades (técnica, máquinas, equipamentos, instrumentos; fabricação, utilização e manejo dos desses; estudo dos aspectos 
econômicos da tecnologia e seus efeitos sobre a sociedade), teve seu emprego equivocado, segundo Vargas (1994, p. 225 apud PINTO, 2004, p. 3): "tecnologia no sentido que é dado pela cultura ocidental é a "aplicação de teorias, métodos e processos científicos às técnicas"”.

Devendo, então, ser entendida como conhecimento científico transformado em técnica, a tecnologia transforma-se, naturalmente, de modo acelerado, com visíveis consequências, seja no mercado de bens, serviços e consumo, no modo de produção, no modo de organização dos trabalhadores, na educação / qualificação dos trabalhadores, ou nas relações sociais.

Hoje é consenso, entre muitos teóricos, que a era industrial se esgotou e que a sociedade do conhecimento emergiu como uma nova modalidade econômico-social, esclarece-nos Ponchirolli (2002):

O mundo, segundo economistas e historiadores, experimentou duas profundas mudanças na base da economia e da estrutura social. Na primeira grande etapa do desenvolvimento econômico os homens passaram de uma economia tribal de caça e coleta para uma economia agrícola. Essa transição começou há aproximadamente 8.000 anos e hoje está quase totalmente completa em todo o mundo, exceto em algumas poucas sociedades primitivas, em áreas como a Bacia Amazônica e Nova Guiné.

$\mathrm{Na}$ segunda grande etapa, os homens passaram da economia agrícola para a economia industrial. Essa etapa teve início na Grã-Bretanha há aproximadamente 250 anos e espalhou-se pela Europa Ocidental, América do Norte e Japão no século XIX. Desde a Segunda Guerra Mundial, a industrialização tem se difundido de maneira extensiva pela Ásia e parte da América Latina.

A terceira etapa da história social dos homens é o desenvolvimento da economia e da sociedade baseadas no conhecimento. Este processo começou nos Estados Unidos há cerca de 25 anos e, atualmente, está se disseminando rapidamente tanto 
nos Estados Unidos como no restante dos países industrializados desenvolvidos do mundo - Canadá, Europa Ocidental e Japão. Suas variáveis críticas e fundamentais são informação e conhecimento (PONCHIROLLI, 2002, p. 31).

Já se tornou truísmo, pois, afirmar que bastante forte tem sido, na atualidade, o impacto social das novas tecnologias, as chamadas tecnologias digitais de informação e comunicação (TDIC), como resultado da fusão de três vertentes técnicas: a informática, as telecomunicações e as mídias eletrônicas - constituindo o que Dreifuss (1996) chama de um "complexo teleinfocomputrônico". Notebooks, tablets, celulares e smartphones já fazem parte do cenário cotidiano, rompendo barreiras de tempo e espaço, influenciando diversas áreas da atividade humana e revolucionando as tradicionais formas de comunicação.

$\mathrm{Na}$ tentativa de precisar o alcance desse impacto, muitos teóricos procuraram descrever seus efeitos sobre as sociedades, nas diversas esferas da vida humana. Como bem coloca Quartiero (1999),

Várias metáforas foram utilizadas por esses autores para explicar a configuração da sociedade contemporânea a partir dessas tecnologias, algumas tendo inclusive se tornado lugar comum: "aldeia global" (MCLUHAN, 1995[1964]), "sociedade pósindustrial" (BELL, 1977), "sociedade pós-capitalista" (DRUCKER, 1993), "sociedade da informação" (TOFFLER [; TOFFLER], 1994), "teia global" (REICH, 1993), “infoera" (ZUFFO, 1996). Num aspecto todos concordam: estaríamos entrando definitivamente numa sociedade do conhecimento. (QUARTIERO, 1999, p.72).

Especificamente no que diz respeito às formas de interação social, a pesquisadora dos estudos linguísticos aplicados Rojo (2012) adverte que, se as mídias anteriores eram destinadas à distribuição 
controlada da informação, a ponto de se falar que elas foram destinadas às massas, a mídia digital e a digitalização (multi)mídia, por sua vez, vêm provocar esse panorama. As ferramentas digitais, como redes sociais diversas (Facebook, Twitter), blogs, chats, GoogleDocs, entre outros, permitem mais que uma simples interação, permitem a interaçãocolaboração, razão pela qual fraturam / transgridem relações de poder preestabelecidas, principalmente as de controle unidirecional da comunicação e da informação e da propriedade de bens culturais imateriais (textos, produções imagéticas e sonoras, ideias). E Lemke (2010) complementa, explicando que, hoje, nossas tecnologias estão nos movendo da era da escrita para a era da autoria multimidiática - numa clara referência ao que Lankshear e Knobel (2007) qualificam como um novo ethos:

os novos letramentos "são mais "participativos", "colaborativos", e "distribuídos" por natureza do que os letramentos convencionais. Eles são menos "dominados por especialistas" que os letramentos convencionais. As regras e normas que os regulam são mais fluídas e menos permanentes que aquelas a que nós tipicamente associamos com os letramentos estabelecidos (LANKSHEAR; KNOBEL, 2007, p. 6).

A educação, por consequência, não está alheia a este processo de interpelação ideológica da sociedade ao uso dos aparatos digitais. ${ }^{3} \mathrm{Na}$

3 “'Interpelação’ é o termo utilizado por Luis Althusser (1971) para explicar a forma pela qual os sujeitos - ao se reconhecerem como tais: 'sim, esse sou eu' - são recrutados para ocupar certas posições-de-sujeito. Esse processo se dá no nível do inconsciente e é uma forma de descrever como os indivíduos acabam por adotar posições-de-sujeito particulares. [...] Ele concebe as ideologias como sistemas de representação, fazendo uma complexa análise de como os processos ideológicos funcionam e de como os sujeitos são recrutados pelas ideologias, mostrando que a subjetividade pode ser explicada em termos de estruturas e práticas sociais e simbólicas. Para Althusser, o sujeito não é a mesma coisa que a pessoa humana, mas uma categoria simbolicamente construída: 'A ideologia... 'recruta' sujeitos entre os 
rede pública de ensino, a crescente informatização das escolas, com a distribuição de microcomputadores, de notebooks aos professores, de tablets aos estudantes são exemplos expressivos dessa interpelação do poder público ao uso da tecnologia na prática docente. De acordo com uma pesquisa quantitativa de abrangência nacional, sobre uso das NTIC em escolas públicas do Ensino Fundamental e Médio de 13 capitais brasileiras, realizada em 2009 pela Fundação Victor Civita, 99\% de um total de 400 escolas já dispõem de computadores funcionando (LOPES et al., 2010). E segundo artigo de opinião publicado pelo Instituto Brasileiro de Opinião Pública e Estatística - IBOPE-, "pelos dados da TIC Educação 2010, todas as escolas situadas na zona urbana têm pelo menos um computador - em média 23 equipamentos por unidade escolar e cerca de 35 alunos por computador. Mais de $80 \%$ delas têm acesso à Internet e destas, 87\% com banda larga" (IBOPE, 2013, s/p.).

Entretanto, como se sabe, não é o aparelhamento tecnológico escolar que trará diferenças significativas na qualidade do ensino no Brasil. Sem falar dos inúmeros casos de falta de acesso à Internet pelos estudantes nas escolas, há muita ilusão na ideia de que as NTIC transformarão o ensino, como em passe de mágica, bastando disponibilizá-las para o uso escolar e deixá-las a cargo do professor. É, sem dúvida, louvável a preocupação por parte das escolas em introduzir os computadores em seu espaço físico, na era digital em que vivemos, mas o problema, explica Freitas (2009, p. 71), é que "a instituição escolar está vivendo essa incorporação como uma intrusão", como algo necessário para se mostrar atualizada, como uma espécie de marketing de qualidade, sem saber por quê, para que e como. Isso parece estar atestado pela mencionada pesquisa da Fundação Victor Civita (LOPES et al., 2010), segundo a qual aproximadamente $70 \%$ dos professores das escolas investigadas admitem não estar preparados para fazer uso do equipamento:

$\mathrm{Na}$ maioria dos casos, os computadores chegaram às escolas sem o respaldo de uma proposta pedagógica

indivíduos... ou 'transforma' os indivíduos em sujeitos [...] por esta operação muito precisa a chamei de interpelação' (1971, p. 146).” (WOODWARD, 2009, p. 59-60). 
(GIMENES, 2001). Muitos projetos envolvendo Educação e Informática têm sido desenvolvidos por agentes externos à comunidade escolar envolvendo os professores apenas como receptores de informação. Nos casos em que não há o envolvimento dos professores ou não lhes são fornecidos formação específica e tempo para inserção no processo de informatização da escola, observa-se como resultado que os professores da escola não aprendem como lidar com tais tecnologias e muito menos como fazer bom uso delas em suas aulas (UNESCO, 2008a, 2008b) ${ }^{4}$ (LOPES et al., 2010, p. 275).

Seguem as principais conclusões desta análise: [...]

- apesar dos dados levantados sobre recursos e infraestrutura serem favoráveis, infraestrutura, formação de professores e problemas com acesso à internet são apontados como os principais problemas para o uso pedagógico do computador;

- a formação oferecida não é percebida como suficiente e adequada, pois falta preparo para o uso da tecnologia centrado em ensino e aprendizagem dos conteúdos escolares;

- o número de professores que usam a tecnologia com seus alunos é ainda pequeno e este uso se dá eminentemente no laboratório de informática;

- na maioria das escolas, as atividades que utilizam tecnologia e são realizadas com os alunos têm pouca complexidade ou usam de recursos simples (LOPES et al., 2010, p. 327-328).

É, portanto, com os estudos acerca dessa temática da atuação docente na era digital que o presente trabalho visa contribuir, buscando problematizar as representações que a academia tem, na voz de especialistas autores de trabalhos acadêmicos recentemente publicados, do sujeito da educação professor, nesse contexto de interpelação ideológica da educação ao uso das NTIC.

\footnotetext{
${ }^{4}$ No original: UNESCO 2008b, 2008c.
} 


\section{Acerca de representação e identidade}

Sabemos, com Pêcheux (1990a), que sujeito, em Análise do Discurso, não é o indivíduo, sujeito empírico, mas o sujeito do discurso, que carrega consigo marcas do social, do ideológico, do histórico. Assim, o discurso produzido por um sujeito pressupõe um destinatário empírico, mas também representado imaginariamente, que se encontra num lugar determinado na estrutura de uma formação social.

Sempre que o sujeito de um discurso toma a palavra, ele mobiliza um funcionamento discursivo que remete a formações imaginárias: o sujeito que enuncia atribui imagens do destinatário, do referente e de si, e essas imagens condicionam o processo de elaboração discursiva, remetendo a mecanismos de funcionamento da linguagem - como relações de sentido, de força e de antecipação, todos condicionados pelas formações imaginárias.

No caso do mecanismo de antecipação, o sujeito coloca-se no lugar do destinatário, podendo, dessa forma, prever o efeito de suas palavras; o locutor regula, pois, seu discurso, conforme os efeitos que tenciona reproduzir no interlocutor. Já na relação de forças, o sentido das palavras é regulado de acordo com o lugar social ocupado pelo sujeito falante; ou seja, a posição social ocupada por este é inerente ao seu dizer. Assim, certos dizeres dominam outros, conforme a representação que se faz do lugar social ocupado por aquele que enuncia.

Tais mecanismos nos permitem, então, dizer que não são os lugares empíricos, ocupados pelos sujeitos, que determinam os dizeres, mas a representação que o sujeito enunciador faz de si, do outro, do outro em relação a si e do referente.

Assim, um discurso não implica necessariamente uma mera troca de informações entre interlocutores, mas, sim, um jogo de "efeitos de sentido" entre os participantes; os sentidos são produzidos por um certo imaginário, que é social e que é, por sua vez, resultado das relações entre poder e sentidos. Logo, nos processos discursivos, vemos funcionar uma série de formações imaginárias que designam os lugares "que A e B se atribuem cada um a si e ao outro, a imagem que eles se fazem de seu próprio lugar e do lugar do outro" (PÊCHEUX, 1990b, p. 82). De modo que interessa-nos lembrar, no presente trabalho, particularmente, o fato 
de que a representação que o sujeito faz do interlocutor direciona a produção de seu discurso.

No registro pós-estruturalista, afirma Silva (2009, p. 90), “a representação é concebida unicamente em sua dimensão de significante, isto é, como sistema de signos, com pura marca material. [...] expressa-se por meio de uma pintura, de uma fotografia, de um filme, de um texto, de uma expressão oral". É, pois, sempre marca ou traço visível, exterior, na medida que, como qualquer sistema de significação, é uma forma cultural de atribuição de sentido, sendo, por isso mesmo, arbitrária, indeterminada e estreitamente ligada às relações de poder.

Segundo Woodward (2009, p. 17),

a representação inclui as práticas de significação e os sistemas simbólicos por meio dos quais os significados são produzidos, posicionando-nos como sujeitos. É por meio dos significados produzidos pelas representações que damos sentido à nossa experiência $\mathrm{e}$ àquilo que somos. [...] A representação, compreendida como um processo cultural, estabelece identidades individuais e coletivas e os sistemas simbólicos nos quais ela se baseia fornecem possíveis respostas às questões: Quem eu sou? $\mathrm{O}$ que eu poderia ser? Quem eu quero ser? Os discursos e os sistemas de representação constroem os lugares a partir dos quais os indivíduos podem se posicionar e a partir dos quais podem falar.

Assim, a todo momento somos interpelados - recrutados e também produzidos-, não apenas no nível do consciente, mas também do inconsciente - pelos sistemas de representação a ocupar determinadas posições-sujeito: o trabalhador honesto, a mãe responsável, o jovem descolado etc., sendo posicionados, e também nos posicionando, de acordo com os campos sociais nos quais atuamos. E é, igualmente, a partir dessas posições-sujeito, a partir de cada uma dessas posições sociais e históricas específicas, que, ao falarmos, representamos alguém ou alguma coisa (HALL, 1990). A representação atua simbolicamente 
para classificar o mundo e nossas relações no seu interior, produzindo identidades, afirma Hall.

Woodward (2009) esclarece que, embora se refiram a dois processos diferentes, o social e o simbólico,

cada um deles é necessário para a construção e a manutenção das identidades. A marcação simbólica é o meio pelo qual damos sentido a práticas e a relações sociais, definindo, por exemplo, quem é excluído e quem é incluído. É por meio da diferenciação social que essas classificações da diferença são "vividas" nas relações sociais. (WOODWARD, 2009, p. 14)

Segundo a autora, a identidade, produto da representação, é relacional, ou seja, é fabricada por meio da marcação da diferença, pois sua conceituação envolve sistemas classificatórios, que mostram como as relações sociais são organizadas - a divisão de uma população em ao menos dois grupos opostos - em termos de nós / eles, eu / outro. De modo que a marcação da diferença é o que separa uma identidade da outra, estabelecendo distinções, na maior parte das vezes, por meio de oposições.

Além de serem interdependentes, segundo a teoria cultural contemporânea, identidade e diferença são o resultado de atos de criação linguística, ou seja, são criadas por meio de atos de linguagem, tendo, pois, de ser nomeadas:

É apenas por meio de atos de fala que instituímos a identidade e a diferença como tais. A definição da identidade brasileira, por exemplo, é o resultado da criação de variados e complexos atos linguísticos que a definem como sendo diferente de outras identidades nacionais (SILVA, 2009, p. 77).

Para Silva, por não serem seres da natureza, mas elementos da cultura e dos sistemas de representação que a engendram, identidade e diferença não podem ser compreendidas fora do sistema de significação 
nos quais adquirem sentido: só têm sentido no interior de uma cadeia saussureana de diferenciação linguística: “('ser isto' significa 'não ser isto' e 'não ser aquilo' e 'não ser mais aquilo' e assim por diante)" (SILVA, 2009, p. 77). Por serem fruto da linguagem, cuja característica principal é a indeterminação, as identidades também se deixam marcar pela instabilidade e indeterminação: não são naturais, nem fixas, nem pré-determinadas.

Identidade e diferença, por outro lado, esclarece-nos o autor, são relações sociais em estreita relação com as relações de poder, estando sujeitas a vetores de força, sendo por isso disputadas:

A afirmação da identidade e a enunciação da diferença traduzem o desejo dos diferentes grupos sociais, assimetricamente situados, de garantir o acesso privilegiado aos bens sociais. [...] São outras tantas marcas da presença do poder: incluir / excluir ("estes pertencem, aqueles não"); demarcar fronteiras ("nós" e "eles"); classificar ("bons e maus"; "puros e impuros"; "desenvolvidos e primitivos"; "racionais e irracionais"); normalizar "nós somos normais; eles são anormais") (SILVA, 2009, p. 81).

E, visto que classificar significa igualmente atribuir valores aos grupos classificados, nesse processo, chamado de normalização há sempre uma oposição binária, em que um dos termos é privilegiado, recebendo um valor positivo, enquanto o outro recebe uma carga negativa: "a identidade normal é 'natural', desejável, única. A força da identidade normal é tal que ela nem sequer é vista como uma identidade, mas simplesmente como $a$ identidade" (SILVA, 2009, p. 83).

Estando, entretanto, sujeitas à historização, as identidades estão constantemente em processo de mudança e transformação, o que tem a ver "não tanto com as questões 'quem nós somos' ou 'de onde nós viemos', mas muito mais com as questões 'quem nós podemos nos tornar', 'como nós temos sido representados' e 'como essa representação afeta a forma como nós podemos representar a nós próprios" (HALL, 2009, p. 109). Concebendo as identidades como 
pontos de apego temporário às posições-sujeito que as práticas discursivas constroem para nós (HALL, 1995), o autor as entende como o resultado de uma bem-sucedida articulação ou "fixação" do sujeito ao fluxo do discurso, uma espécie de sutura bem feita do sujeito a uma posição-sujeito, o que "exige não apenas que o sujeito seja 'convocado', mas que o sujeito invista naquela posição” (HALL, 2009, p. 112).

Transportando para a situação acadêmica em tela, em que os protagonistas da cena enunciativa investigada (os pesquisadores) produzem dizeres (na forma de artigos científicos) endereçados a seus leitores (público em geral, incluindo outros pesquisadores), o que os dados estão a nos revelar, como mostraremos, é uma interpelação do sujeito professor a assumir uma determinada identidade, segundo a representação que tais especialistas têm das ações e dizeres próprios da ocupação de seus lugares, de suas posições-sujeito (PÊCHEUX, 1995). Segundo esse jogo, cabe ao pesquisador - enquanto aquele que, em princípio, sabe-, enunciar uma verdade ao leitor - aquele que, em princípio, não sabe. Mais especificamente, os dizeres e as ações do sujeito-autor pesquisador se fazem segundo o que ele imagina que seja ele mesmo, o que seja o leitor e o que seja o referente. Vejamos como isso se dá relativamente aos excertos visitados.

\section{A representação acerca do professor na era digital por artigos acadêmicos}

De um modo geral, pudemos perceber que os artigos investigados consistem num discurso no qual se observa, a despeito da diferença entre as áreas de conhecimento de seus autores, uma impressionante regularidade na enunciação de uma verdade acerca do professor contemporâneo. Essa verdade, segundo pudemos notar, emerge na forma de uma grande proposição, composta por quatro enunciados ou formações linguísticas complementares, que carregam em si, respectivamente, cada um dos traços que comporiam esse imaginário discursivo acerca do sujeito da educação professor. Apresentamos a forma sumarizada desses enunciados: $O$ professor está diante de um desafio; O professor tem um novo papel; O professor deve ser um 
mediador; O professor precisa aprender para ensinar.

Evidentemente, tais enunciados não aparecem materializados com essa estrutura sintática na superfície linguística dos textos investigados, por estarem contextualizados e a serviço do sentido pretendido pelo enunciador em seu artigo. Porém, o que se observa é que, embora não apareçam necessariamente assim estruturados sintaticamente ou linguisticamente formados, nem nessa mesma ordem, nem conjugados entre si, em cada um dos textos analisados, sua enunciação ocorre sempre na modalidade alética. ${ }^{5}$ Considerada a maneira com que o falante se expressa no conteúdo da frase que diz, "a modalidade alética refere-se às noções de verdade e / ou falsidade das proposições, podendo os enunciados de uma ciência ser necessária ou possivelmente verdadeiros" (FERNANDES, M. B. S., 2012, p. 157).

Abaixo seguem alguns recortes discursivos (RD) representativos do primeiro enunciado ( $O$ professor está diante de um desafio):

RD1: Instituir mudanças na escola, adequando-a às exigências da sociedade do conhecimento, constitui hoje um dos maiores desafios educacionais (SOARES-LEITE e NASCIMENTO-RIBEIRO, 2012, p. 179).

RD2: Na atualidade, fala-se que as TIC têm um grande potencial para inovar a prática pedagógica, melhorando a qualidade do ensino e, portanto, da educação. No entanto, como se vem discutindo até aqui, a implantação dessas tecnologias na escola tem desafiado o professor no sentido de aprender a manipular o computador, usar seus aplicativos e a Internet, além de saber os porquês e como integrá-los à prática diária na escola (MOLIN; RAABE, 2012, p. 256).

RD3: A prática docente com o uso de tecnologias

\footnotetext{
${ }^{5}$ De acordo com Castilho e Moraes de Castilho (2002), modalidade é a estratégia que consiste em apresentar o conteúdo proposicional numa forma assertiva (afirmativa ou negativa), interrogativa (polar ou não polar) ou jussiva (imperativa ou optativa).
} 
digitais se constitui em grande desafio aos professores nos tempos atuais (GARCIA et al., 2011, p. 79).

RD4: Parece possivel afirmar que um professor multiletrado pode provocar mudanças em seu fazer pedagógico e um realinhamento às necessidades de seus alunos para os desafios da era do ciberespaço (DIAS, 2012, p. 861).

O emprego da expressão desafio sugere que há uma disputa em jogo, uma convocação, em que alguém é instigado a ultrapassar um grande obstáculo, a realizar algo além de suas competências ou habilidades. ${ }^{6}$ Enquanto os sujeitos-enunciadores de RD1 afirmam que o desafio que está posto aos professores nos tempos atuais está na adequação escolar às exigências da sociedade do conhecimento, os de RD2 entendem que tal desafio está na implantação das tecnologias digitais de informação e comunicação na escola; os de RD3, que está na prática docente com o uso dessas tecnologias; e o de RD4, que tal desafio está no multiletramento docente demandado pelo ciberespaço.

Quando consideramos o segundo enunciado ( $O$ professor tem um novo papel), parece que esse desafio a que os autores mencionados se referem adquire contornos mais delineados:

RD5: Superar o paradigma tradicional ainda hegemônico implica, entretanto, (re)pensar o papel e as competências docentes para lidar com necessidades atuais de formação bem como a organização da sala de aula, já que sua configuração não é mais a mesma de anos atrás (GARCIA et al., 2011, p. 79).

RD6: Além disso, as mudanças tecnológicas também modificam as novas gerações que surgem, e por conseguinte, surge um novo contexto educacional que exige uma nova postura por parte do professor.

\footnotetext{
${ }^{6}$ Conforme $<$ http://www.dicio.com.br/desafio/>. Acesso em: 17 fev. 2015.
} 
Desse modo, este artigo objetiva discorrer acerca desse novo contexto educacional que surge, visando esclarecer qual é o papel que o professor deveria assumir na contemporaneidade (ALDA, 2012, p. 1).

RD7: A sala de aula não é mais a mesma. A tecnologia [...] passa (ou pelo menos tenta) fazer parte do cotidiano [...] Todavia, mudar as formas de aprender dos alunos requer também mudar as formas de ensinar de seus professores [...] rever o papel da escola e, principalmente, do professor [...] $A$ inclusão das novas tecnologias na educação exige um novo profissional mais flexível e maduro (SOARES-LEITE e NASCIMENTO-RIBEIRO, 2012, p. 184).

RD8: Entendemos aqui que é papel do docente conhecer novas possibilidades de escrita a partir dos novos gêneros textuais que emergem com o advento das novas tecnologias (SILVA, 2011, p. 35).

RD9:No que diz respeito às reconfigurações identitárias dos agentes educacionais, particularmente em relação à nova prática docente, nos deparamos com uma questão decisiva: o papel do professor diante do acesso cada vez maior de informaç̃̃es, as quais são instantaneamente obtidas por aparelhos tais como notebooks, tablets, celulares etc. (ZUIN; ZUIN, 2011, p. 224).

RD10: O ensino hoje requer mudança no papel do profissional de educação que possa estimular o aluno a buscar e selecionar as fontes de informação voltadas ao ensino e à pesquisa, estudando-as e recriando-as (MOURA; BRANDÃO, 2013, p. 2).

Trata-se, como se pode perceber, de impor ao professor a superação do desafio aludido, não apenas no sentido de inserir as tecnologias digitais em sua prática docente, mas no sentido de fazê-lo transformar-se como tal, proceder a uma mudança, a uma alteração de si 
mesmo. Segundo o dicionário Aurélio, mudança é o "ato ou efeito de mudar(-se)" e, mudar, "alterar, modificar; fazer apresentar-se sob outro aspecto; transformar, converter; sofrer alteração, modificação" (FERREIRA, 19--, p. 951); o que nos remete à ideia de transformação, alteração de um estado. Assim, a imposição, por parte dos sujeitospesquisadores, vem na forma de uma exortação a uma ação de grande porte a ser empreendida pelo professor: (re)pensar o papel e as competências docentes (RD5), [ter] uma nova postura (RD6), [ser] mais flexível e maduro (RD7), conhecer novas possibilidades de escrita a partir dos novos gêneros textuais (RD8), ou [proceder] a uma mudança no [seu] papel [enquanto] profissional da educação (RD10). E a convocação se dá discursivamente pelo emprego das formas verbais do presente do indicativo: implica [repensar], exige [nova postura / novo profissional], requer [rever o papel / mudança no papel], e é [papel conhecer] - que, como vimos, caracterizam a enunciação de uma verdade.

A natureza dessa transformação a que é chamado o professor a realizar vai aparecer melhor configurada no terceiro enunciado a que aludimos ( $O$ professor deve ser um mediador), conforme os excertos que seguem:

RD11: Em um mundo conectado em rede, com inúmeras trocas de informação e rapidez de interação, o papel do professor, em suma, é auxiliar o aluno na busca pelo conhecimento, ser um mediador entre o aluno $e$ a aprendizagem. $O$ professor pós-moderno deve estar em sincronia com a contemporaneidade, saber utilizar as tecnologias em prol de um ensino mais eficiente e eficaz, trabalhar em parceria com o aluno e, além de tudo isso, ser consciente de que não é o detentor de todo o conhecimento. Hoje, é necessário ensinar nossos alunos a refletir, questionar, raciocinar $e$ compreender a nossa realidade, para que possam contribuir com a sociedade e construir opiniões próprias (ALDA, 2012, p. 3).

RD12: O que fazer com um aluno que já nasceu na 
era da informação e que já traz consigo a experiência de um mundo tomado pela velocidade dos acontecimentos? A resposta torna-se simples: respeitando e avaliando a base de conhecimento já incorporada pelo estudante quando ele chega à escola, conduzindo-o a pesquisa e produção do conhecimento, mediando-o em sua caminhada na carreira estudantil, incorporando novos conhecimentos no cotidiano em sala. Para tanto o professor pode e deve incorporar as novas tecnologias em seu método de ensino. Falando a "língua do aluno" [...] (VIEIRA, 2012, p. 97).

RD13: O uso das novas tecnologias da comunicação e informação representa uma grande inovação na educação, pois propicia o desenvolvimento das produções em colaboração, podendo instigar o espírito investigativo tanto dos alunos quanto dos professores sendo que estes poderão apropriar-se do uso das tecnologias para mediar os trabalhos dos estudantes, sentindo-se desafiados a buscar condições mais adequadas para o processo de aprendizagem interativo e dinâmico (MOURA; BRANDÃO, 2013, p. 3).

A grande mudança enunciada pelos sujeitos-especialistas relativamente ao papel do professor, como está posto nesses recortes, aparece atrelada a uma postura de mediação do conhecimento. Ensinar, agora, passa a ser mediar: "intervir como árbitro ou mediador", sendo mediação "intervenção, intercessão, intermédio" (FERREIRA, [s.d.], p. 903); "ação de auxiliar como intermediário entre indivíduos ou grupo de pessoas" (dicionário online de português). ${ }^{7}$ Pressupõe-se, pois, haver uma dupla possibilidade de atuação pedagógica por parte desse sujeito da educação, quando se considera os efeitos da presença das NTIC no processo de ensino-aprendizagem: uma atuação anterior ao advento dessas tecnologias e uma atuação no interior delas. E a explicação para

\footnotetext{
${ }^{7}$ Disponível em: <http://www.dicio.com.br/mediacao/>. Acesso em: 17 fev.2015.
} 
essa mudança de papel é feita por um dos próprios sujeitos-autores aqui pesquisados:

A educação e o sistema educativo sofreram grandes mudanças nos últimos tempos. A partir do século XX, os avanços tecnológicos popularizaram o acesso à informação, modificando a maneira como vivemos e, consequentemente, a maneira como aprendemos. A nossa sociedade, atualmente, está em rede; e isso provocou mudanças marcantes. A aprendizagem não é mais individual, mas sim coletiva. O conhecimento é construído em grupo e incontestavelmente está mais acessível. Logo, qual é o papel do professor hoje? Qual é o impacto do professor numa sociedade em rede, com tantas oportunidades de aprendizagem?

Anteriormente, o professor era o único participante ativo da sala de aula; aquele que detinha o conhecimento e que transmitia para os alunos todo o seu estudo e sabedoria de forma linear, passando apenas do professor para os alunos, sem grandes reflexões ou visão crítica dos conteúdos. A educação tradicional era centrada no professor, fundamentalmente baseada em texto e excessivamente expositiva. Porém, a nova geração está acostumada a agir em vez de passivamente assistir. Com a evolução das tecnologias e da sociedade, além das oportunidades de aprendizagem, os alunos também mudaram (ALDA, 2012, p. 2).

Assim, o raciocínio que parece sustentar a proposição da verdade enunciada pelos sujeitos-especialistas é o seguinte: se para atuar em sala de aula em conexão com as tecnologias digitais o professor da atualidade enfrenta o desafio de mudar seu papel para o de mediador do conhecimento, então - eis o último enunciado que compõe a proposição, o professor precisa aprender para ensinar. É o que depreendemos do nosso último bloco de recortes: 
RD14: Neste ponto, podemos pensar então na importância de expandir o repertório tecnológico dos docentes como meio de instrumentalizá-los para uma prática pedagógica fundamentada em um novo paradigma, diferente do tradicional, que mantêm distantes alunos e professores (GARCIA et al., 2011, p. 79).

RD15: Discute-se a importância da atenção no ensino/aprendizagem na universidade em conexão com as novas tecnologias, propondo-se de forma simples, o aprimoramento do desempenho do professor universitário em relação a estas tecnologias (MARCHIORI, MELO; MELO, 2011, p. 1).

RD16: $E$ evidente que os professores necessitam acompanhar as mudanças a fim de adaptar-se. Porém, tendo em vista que a maioria dos professores está acostumada com o ensino tradicional, linear, baseado em textos, prováveis desafios podem vir a ser enfrentados por professores, entre os quais, destacam-se a necessidade de letramento digital, a resistência ao uso de novas tecnologias e à formação continuada. Por isso, é de suma importância para o professor buscar um aperfeiçoamento contínuo, a fim de adaptar-se às novas metodologias que surgem para auxiliar o processo de ensino e aprendizagem. Devemos sempre acompanhar a evolução, a fim de buscar o conhecimento para compartilhá-lo (ALDA, 2012, p. 4).

RD17: Tornam-se necessárias, então, mudanças no agir pedagógico do professor de inglês que só poderão ser alcançadas por meio de um processo de formação que vise ao desenvolvimento das práticas multiletradas da contemporaneidade (DIAS, 2012, 862).

RD18: [...] este artigo apresenta os resultados de uma pesquisa que buscou conhecer as percepções de um grupo de professores sobre possiveis 
transformações ocorridas em suas práticas pedagógicas após terem participado, nos anos de 2008 e 2009, do curso de formação continuada 'Introdução à Educação Digital'. Evento promovido, em todo o País, pelo Programa Nacional de Formação Continuada em Tecnologia Educacional Proinfo Integrado. O objetivo deste curso é contribuir para a inclusão digital dos profissionais da educação, visando familiarizar, motivar e preparar os professores e gestores para a utilização dos recursos e serviços mais usuais dos computadores $e$ da Internet (MOLIN; RAABE, 2012, p. 250).

RD19: Diferentemente da perspectiva das politicas públicas atuais, que privilegiam a formação continuada do professor para o trabalho com tecnologias digitais na sala de aula, a perspectiva defendida neste texto é a de alterações profundas na formação inicial dos professores em nível superior, que circunscrevam a incorporação das mídias em todas as dimensões da prática do professor universitário (ARRUDA, 2013, p. 275).

Ora, uma vez afirmada a importância de [se] expandir o repertório tecnológico dos docentes, do aprimoramento do desempenho do professor, do seu aperfeiçoamento contínuo, da mudança em seu agir pedagógico, de preparar os professores e gestores para a utilização dos recursos e serviços mais usuais dos computadores e da Internet, e de proceder a alterações profundas na formação inicial dos professores em nivel superior, afirma-se a sua necessidade de capacitação, de aprender para poder ensinar, já que, por meio de um não-dito, afirma-se, igualmente, que os professores estão despreparados, em termos de conhecimento didático-tecnológico, para dar conta do anunciado desafio.

No intuito de concluir nossa análise de tais enunciados, é forçoso reconhecer que, segundo a Análise de Discurso derivada da obra de Michel Pêcheux, sem sombra de dúvida, estamos diante de um discurso, porque o que é enunciado é enunciado de um lugar ideologicamente marcado: designa um autor, uma instância produtora, uma função-sujeito 
dadas as posições sociais dos envolvidos (especialistas, público leitor) e manifesta um sentido segundo tais posições (e em relação às formações ideológicas nas quais essas posições se inscrevem).

Estamos diante de um discurso, porque se trata de um conjunto de enunciados que derivam de (ou materializam) uma mesma formação discursiva (FOUCAULT, 1987[1969]; PÊCHEUX, 1990b), ou seja, implica regularidades (constitui uma constância de unidade na dispersão dos acontecimentos, apresenta uma identidade e persistência de temas); existe em um tempo e espaço físico-social, refletindo condições de produção historicamente definidas (a atualidade, a universidade); e refere-se ao que se pode dizer somente em determinada época e espaço social (ao que tem lugar e realização a partir de condições de produção específicas).

Estamos ainda diante de um discurso, porque, ao ser produzido, o enunciado constitui uma ação social em um contexto situacional historicamente determinado: primeiro, é um procedimento de controle por meio da interdição: impõe regras de exclusão aos sujeitos do discurso (estabelece direitos e proibições em relação ao ato de falar, quem pode ter acesso a certos discursos e quem deve ser interditado, já que para entrar na ordem do discurso é preciso ser qualificado para tal); segundo, é um procedimento de controle por meio da vontade de verdade (FOUCAULT, 1999a[1971]) - retrata como o saber é aplicado na sociedade, como é valorizado, distribuído, repartido, atribuído-; e, finalmente, em sua relação com o sujeito, incita, provoca, faz deslocar.

Mais do que isso, estamos diante de um discurso que funciona como um dispositivo de poder (FOUCAULT, 1999c[1988]). Vamos lembrar que, para Foucault (1999b[1987]), o poder não está localizado em nenhum ponto específico da estrutura social, não é propriedade de ninguém; está em toda parte, provém de todos os lugares; é focalizado em microinstâncias, por ser um exercício integrante do cotidiano, que promove a constituição da identidade dos sujeitos; é um modo de ação de alguns sobre os outros (uma maneira de agir sobre a ação dos outros para conduzir condutas); existe (é observável) sob a forma de relações perpassadas pelos discursos; funciona em rede e promove a docilidade e a submissão daqueles sobre quem ele recai.

Estamos, pois, diante de um dispositivo de poder, porque se trata 
de um tipo de formação que, em determinado momento histórico, surge para responder a uma urgência (FERNANDES, C. A., 2012, p. 66): no presente caso, atuar pedagogicamente num mundo dominado pelas tecnologias digitais de informação e comunicação. É produzido a partir de um regime de verdade socialmente determinado, uma vez que, conforme Foucault (2009 [1979], p.12), "cada sociedade tem seu regime de verdade, sua 'política geral' de verdade: isto é, os tipos de discurso que ela acolhe e faz funcionar como verdadeiros".

\section{5 À guisa de palavras finais...}

A leitura analítica a que procedemos desse conjunto de artigos acadêmicos atuais nos revela que está em curso, no campo educacional, a exaltação de um saber pós-moderno que toma como foco central as tecnologias digitais de informação e comunicação; ou seja, há uma vontade de verdade (FOUCAULT, 1999a [1971]) que relaciona educação e tecnologia sendo enunciada, na contemporaneidade, por sujeitos especialistas referendados pela sociedade.

Para Foucault, toda produção discursiva implica, no nível da subjetividade, certa vontade de conhecer as verdades do discurso. E como bem coloca Noto (2010),

um discurso só é aceito em uma época quando segue a racionalidade, o modo de legitimar a separação entre o verdadeiro do falso dessa mesma época. Com outras palavras, um discurso só é aceito se acata o valor legitimado em sua época de certa separação do verdadeiro e o falso; isto é, se diante do verdadeiro e do falso se posiciona de acordo com a vontade de verdade vigente em sua época. [...] a aceitabilidade de um enunciado ou de um discurso não provém da relação de adequação entre aquilo que é dito e a realidade (noção de verdade enquanto adequação), nem tampouco da coerência interna do discurso (noção de verdade enquanto coerência). Para que um enunciado seja aceito em uma época, para que possa 
ser legitimamente dito, para que esteja no verdadeiro, basta seguir certas regras ditadas pela disciplina a qual pertence. E Foucault (2002, p. 431) confirma: "não nos encontramos no verdadeiro senão obedecendo às regras de uma 'polícia' discursiva que devemos reativar em cada um de nossos discursos" (NOTO, 2010, p. 21). ${ }^{8}$

Ao que parece, então, a proposição a que nos referimos, composta pelos quatro enunciados apontados, independentemente de dizer ou não a verdade, pode ser legitimamente dita e aceita em nossa época desde que siga certas regras internas à disciplina à qual pertence. Pois bem, se essa vontade de verdade parte de intelectuais cuja "polícia" discursiva, intrínseca à própria classe, tem as regras de sua disciplina obedecidas (tratam de objetos específicos, utilizam certos conceitos e inscrevem-se em um determinado horizonte teórico), isso já parece bastar para que seus enunciados estejam no verdadeiro e sejam, pois, aceitos em nossa época.

$\mathrm{Na}$ medida que, segundo o aporte foucaultiano, "o dispositivo é, antes de tudo, uma máquina que produz subjetivações e somente enquanto tal é também uma máquina de governo (AGAMBEN, 2009, p. 46 apud FERNANDES, C. A., 2012, p. 68), essa vontade de verdade enunciada academicamente é destinada a produzir, a moldar e a controlar a subjetividade docente, constituindo uma prática contemporânea de subjetivação do professor, fazendo-o mover-se para tornar-se outro, diferente de si mesmo. Vamos lembrar, com Foucault, que modos de subjetivação são procedimentos de constituição de subjetividade.

Estamos, pois, diante um processo de interpelação ideológica, que funciona como uma força sobre o sujeito da educação professor, convocando-o à subjetivação que interessa ao poder - como já apontado, "o poder de definir a identidade e de marcar a diferença não pode ser separado das relações de poder" (SILVA, 2009, p. 81). E isso se dá por induzir a uma ética educacional geral de acesso ao conhecimento técnico-pedagógico atrelado ao domínio e ao uso das tecnologias digitais

${ }^{8}$ Grifos da autora. 
na prática docente. Tal interpelação é fundamental para demarcar fronteiras sociais e possibilitar o pertencimento desse sujeito a um determinado grupo, que, sabemos, hoje já está se constituindo com um status pedagógico e político privilegiado.

Ao se impor discursivamente $a$ (e não uma) identidade professoral na contemporaneidade como aquela que articula educação e tecnologia, inclui-se no grupo dos "bons professores" todos aqueles que invest(ir)em nessa posição-sujeito; e exclui-se, evidentemente, todos os outros, os "maus professores", que não se identifica(re)m com tal posicionamento discursivo. Normaliza-se, assim, a identidade docente, elegendo uma identidade específica como a normal e desejável para os tempos atuais, o parâmetro em relação ao qual as outras identidades docentes são avaliadas e hierarquizadas. Afinal, como já dissemos, identidade e diferença são estreitamente dependentes da representação e "quem tem o poder de representar tem o poder de definir e determinar a identidade" (SILVA, 2009, p. 91).

Segundo o gesto interpretativo que ora fazemos, intenta-se, portanto, pela via discursiva, uma governamentalidade (FOUCAULT, 2009 [1979]), um campo estratégico de relações de poder no contexto acadêmico e educacional, no qual o poder é compreendido em seu sentido mais amplo como a estruturação de um campo possível da ação de outras pessoas. Trata-se, pois, de um processo discursivo de fabricação do "novo professor" - ou, poderíamos dizer, de criação do "professor pós-moderno"-, aquele que estaria apto para atuar profissionalmente na era digital.

Resta-nos, contudo, indagar: a serviço de que ou de quem isso opera?

Esse processo, acreditamos, está a serviço das demandas da sociedade de consumo regida pela lógica neoliberal de governo; em outras palavras, trata-se de uma forma de governamentalidade neoliberal no campo da educação.

Em interessante análise acerca das relações entre política educacional e governo, Peters (2010) investiga, com base na noção

\footnotetext{
${ }^{9}$ Ou governamento, nos termos de Veiga-Neto (2007 [2003]), p. 123): “governamento é tomado no sentido de 'dirigir as condutas' de indivíduos ou pequenos grupos humanos: governar as crianças, as mulheres, a família etc."
} 
foucaultiana de discurso, as formas pelas quais a educação tem sido discursivamente reestruturada, sob o signo do Homo economicus, como uma forma de governamentalidade neoliberal. Segundo o pensamento de que há na atualidade um progressivo alargamento do território econômico a todos os comportamentos que envolvem alocação de recursos, o autor explica, com base em Burchell (1993), como se configura uma cultura de empresa: com a generalização da forma empresarial a todas as formas de conduta, ou seja, com a institucionalização do jogo da empresa como um princípio generalizado de organização da sociedade como um todo. E mostra, igualmente, como a promoção dessa cultura de empresa constitui a característica principal do estilo neoliberal de governo, do qual a educação não escapa:

$\mathrm{Na}$ área da educação, por exemplo, exige-se que as escolas individuais e outros estabelecimentos educacionais ajam cada vez mais de acordo com uma espécie de lógica do "mercado" competitivo, no interior de um sistema inventado de formas institucionais e práticas. [...] exige-se que cada escola, individualmente, funcione cada vez mais como uma quase-empresa independentemente administrada, em competição com outras escolas. Elas são encorajadas a se esforçar por adquirir um status ou valor especial no mercado de serviços escolares. Elas têm que promover a si próprias para atrair mais alunos do tipo certo de forma que possam obter melhores resultados nos testes e possam, assim, continuar a atrair os alunos certos, enviados por "pais-consumidores", obtendo fundos crescentes do Estado e de fontes privadas... (BURCHELL, 1993, p. 274 apud PETERS, 2010, p. 220).

Segundo Peters, palavras como empresa e cultura da empresa são os principais significantes desse novo discurso, visto que fornecem uma prescrição de conduta para a educação, que passa a ser vista como um setor chave na promoção da vantagem competitiva econômica nacional e na prosperidade nacional futura: 
No passado, houve uma ênfase demasiada nos objetivos sociais e culturais e uma ênfase insuficiente nos objetivos econômicos dos sistemas educacionais. Daqui para diante, devemos investir pesadamente na educação como a base para um crescimento econômico futuro, redesenhando os sistemas educacionais de forma que eles atendam às necessidades do comércio e da indústria. $\mathrm{O}$ imperativo econômico é o que predomina (PETERS, 2010, p. 222).

Contudo, o que mais chama a atenção na análise de Peters e que nos interessa particularmente é a alusão ao papel das NTIC nesse contexto. Segundo ele, a noção de cultura da empresa também se atualiza ideologicamente, adequando ao tempo presente o discurso da iconografia popular do passado:

Como uma metáfora para o discurso dos pósindustriais anos 90 - na era da assim chamada "nova ordem mundial" do fim da guerra fria, do desaceleramento da corrida armamentista e dos acordos de paz-, o foco passou da exploração do medo da iminente destruição envolvida na rivalidade das superpotências para o papel que as novas tecnologias de informação, das comunicações e do computador (entre outras) podem exercer no declínio econômico, face à competição internacional e à necessidade de se alinhar às nações líderes na ocupação do centro da arena internacional (PETERS, 2010, p. 223).

É, então, com base nessa noção de alargamento da economia, com consequente "invasão / contaminação" do universo educacional, baseado no postulado comportamental conhecido como Homo economicus, que nos parece possível compreender como se tornam 
satisfeitas as condições de aceitabilidade da verdade do discurso acadêmico acerca da docência na era digital. Ou seja, é na redescoberta moderna do principal princípio da economia liberal clássica - "de que as pessoas devem ser tratadas como maximadores racionais da utilidade para reforçar seus próprios interesses (definidos em termos de posições mensuráveis de riqueza) na política, assim como em outros aspectos da conduta" (PETERS, 2010, p. 221) ${ }^{10}$-, que o discurso acadêmico acerca do professor contemporâneo em tempos de tecnologias digitais encontra seu sentido.

Afinal, em função de que se dá a aludida interpelação ideológica que subjetiva o profissional da educação a uma nova identidade atrelada às NTIC, se não do abastecimento do mercado com o discurso da qualidade referente ao campo educacional? Como bem observa Gentili (2007 [1994]), uma das principais motivações dessa retórica da qualidade advém da necessidade de traçar estratégias que assegurem maior e melhor adaptabilidade, ajuste e acomodação a um mercado em mutação: "nenhum empresário pode ser tão incompetente (com risco de desaparecer rapidamente do mundo dos negócios) a ponto de não considerar que a qualidade é importante na medida que garante a produtividade (ou a incrementa), fator que lhe assegura manter sua rentabilidade ou ainda aumentá-la" (GENTILI, 2007[1994], p.133).

Não é à toa, aliás, que, nos excertos analisados, encontramos alusão à qualidade e à eficiência do sistema educacional: "Na atualidade, fala-se que as TIC têm um grande potencial para inovar a prática pedagógica, melhorando a qualidade do ensino e, portanto, da educação" (RD2); "O professor pós-moderno deve estar em sincronia com a contemporaneidade, saber utilizar as tecnologias em prol de um ensino mais eficiente e eficaz" (RD11). ${ }^{11}$

Ora, que outro mecanismo mais perspicaz de atribuição de qualidade se pode impingir a um sistema educacional, se não um dispositivo de governo que, concebendo seu principal ator, o professor, como um maximador racional da utilidade, o interpela à subjetivação a uma nova identidade? Vale lembrar, tal como afirma Ramos (1992 apud

\footnotetext{
${ }^{10}$ Grifo nosso.

${ }^{11}$ Grifos nossos.
} 
GENTILI, 2007 [1994], p. 143), que "a qualidade se decide no topo (direção da escola), mas se constrói de baixo para cima (o que é possível através dos comitês)", de modo que tudo se resume na boa vontade dos atores educacionais quanto à instalação, criação e reprodução da qualidade em suas próprias escolas.

$\mathrm{Na}$ linha do que Gentili (1993 apud GENTILI, 2007[1994], p.151) caracterizou como "a ideologia das pedagogias fast food", tal governamentalidade, parece-nos, "inspira-se em três concepções que compartilham a escola tradicional e os modernos Mc Donald's: a noção de mérito, a função exemplificadora do quadro de honra e a filosofia do “você pertence à equipe dos campeões"' (GENTILI, 2007[1994], p.151).

É, enfim, a necessidade de impor uma lógica de subordinação mercantil na educação que explica semelhante armadilha discursiva.

\section{Referências}

AGAMBEN, G. O que é contemporâneo e outros ensaios. Tradução de Vinicius Nicastro Honesko. Chapecó: Argos, 2009.

ALDA, L. S. Novas tecnologias, novos alunos, novos professores? Refletindo sobre o papel do professor na contemporaneidade. In: SEMINÁRIO INTERNACIONAL DE LETRAS, 12, 2012, UNIFRA, Santa Maria. Anais... Santa Maria, 2012. p. 1-6.

ALTHUSSER, L. Lenin and philosophy, and other essays. London: Left Books, 1971.

ARRUDA, E. P. A formação do professor no contexto das tecnologias do entretenimento. ETD. Educação temática digital. Campinas, v. 15, n. 2, p. 264-280, 2013.

BELL, D. O advento da sociedade pós-industrial. São Paulo: Cultrix, 1977.

BURCHELL, G. Liberal government and techniques of the self. Economy and society, v. 22, n. 3, p. 267-283, 1993.

<http://dx.doi.org/10.1080/03085149300000018> 
CASTELLS, M. A sociedade em rede. A era da informação: economia, sociedade e cultura. São Paulo: Paz e Terra, 1999.

CASTILHO, A.; MORAES DE CASTILHO, C. Advérbios modalizadores. In: ILARI, R. (Org.) Gramática do português falado: níveis de análise linguística. V. 2. Campinas, SP: Editora da Unicamp, 2002. p. 199-247.

DIAS, R. WebQuests: tecnologias, multiletramentos e a formação do professor de inglês para a era do ciberespaço. Revista brasileira de linguística aplicada, Belo Horizonte, v. 12, n. 4, p. 861-882, 2012.

DREIFUSS, R. Época das perplexidades. Petrópolis: Vozes, 1996.

DRUCKER, P. Sociedade pós-capitalista. São Paulo: Pioneira, 1993.

FERNANDES, C. A. Discurso e sujeito em Michel Foucault. São Paulo: Intermeios, 2012.

FERNANDES, M. B. S. Breve abordagem da categoria discursiva modalidade. 2012. Disponível em: $<$ http://www.filologia.org.br/abf/rabf/9/157.pdf $>$. Acesso em: $17 \mathrm{fev}$. 2015.

FERREIRA, A. B. H. Novo dicionário da língua portuguesa. 11. imp. Rio de Janeiro: Nova Fronteira, [s.d.].

FERREIRA, A. B. de H. Novo Dicionário Aurélio. Rio de Janeiro: Nova Fronteira, [19--].

FOUCAULT, M. A arqueologia do saber. Tradução de Luiz Felipe Baeta Neves. 3. ed. Rio de Janeiro: Forense Universitária, 1987. Edição original: 1969.

. A ordem do discurso. Tradução de Laura Fraga de Almeida Sampaio. 5. ed. São Paulo: Loyola, 1999a. Edição original: 1971.

. A governamentalidade. In: - Microfisica do poder. Organização, introdução e revisão técnica de Roberto Machado. 27. imp. São Paulo: Graal, 2009. p. 277-293. Edição original: 1979.

. Vigiar e punir: nascimento da prisão. Tradução de Raquel Ramalhete. 20. ed. Petrópolis: Vozes, 1999b. Edição original: 1987. 
. História da sexualidade I: a vontade de saber. Tradução de M. Thereza da Costa Albuquerque, J. A. Guilhon Albuquerque. 13. ed. Rio de Janeiro: Graal, 1999c. Edição original: 1988.

. As palavras e as coisas. São Paulo: Martins Fontes, 2002.

FREITAS, M. T. de A. A formação de professores diante dos desafios da cibercultura. In: . (Org.). Cibercultura e formação de professores. Belo Horizonte: Autêntica, 2009. p. 57-74.

GARCIA, M. F.; RABELO, D. F.; SILVA, D. da.; AMARAL, S. F. do. Novas competências docentes frente às tecnologias digitais interativas. Teoria e Prática da Educação, Campinas, v. 14, n. 1, p. 79-87, 2011.

GENTILI, P. A. A. La ideologia de las "pedagogias fast food". 1993, mimeo.

. O discurso da "qualidade" como nova retórica conservadora no campo educacional. Tradução de Vania Paganini Thurler. In: SILVA, T. T. da. (Org.). Neoliberalismo, qualidade total e educação: visões críticas. 12. ed. Petrópolis: Vozes, 2007. p. 110-177. Edição original: 1994.

GIMENES, M. C. A utilização do computador na educação. Educere: revista da educação, Toledo, v. 1, n. 2, p. 19-32, 2001.

IBOPE. Instituto Brasileiro de Opinião Pública e Estatística. TIC na educação: o acesso vem avançando. E a aprendizagem? 2013.

Disponível em: <http://www.ibope.com.br/pt$\mathrm{br} /$ conhecimento/artigospapers/Paginas/TIC-na-Educacao-O-acessovem-avancando--E-a-aprendizagem-.aspx>. Acesso em: 17 fev. 2015.

HALL, S. (Org.) Representation: cultural representations and signifying practices. London: Sage / The Open University, 1990.

. Fantasy, identity, politics. In: CARTIER, E.; DONALD, J.; SQUITES, J. (Org.) Cultural remix: theories oh politics and the popular. London: Lawrence \& Wishart, 1995. p. 79-93.

. Quem precisa de identidade? In: SILVA, T. T. da. (Org.) Identidade e diferença: a perspectiva dos Estudos Culturais. 9. ed. São Paulo: Vozes, 2009. p. 103-133. 
LANKSHEAR, C.; KNOBEL, M. Sampling "the new" in new literacies. In: Lang, 2007. p. $\overline{25-48 .}$

LEMKE, J. L. Letramento metamidiático: transformando significados e mídias. Trabalhos em linguística aplicada. Campinas, v. 49, n. 2, 2010. Disponível em: $<$ http://www.scielo.br/pdf/tla/v49n2/09.pdf $>$. Acesso em: 17 fev. 2015.

LOPES, R. de D. et al. O uso dos computadores e da internet em escolas públicas de capitais brasileiras. In: Estudos \& pesquisa educacionais, v. 1, 2010. p. 275-335. Disponível em: <http://www.fvc.org.br/estudos-epesquisas/avulsas/estudos 1-7-uso-computadores.shtml?page $=3>$. Acesso em: 17 fev. 2015.

MARCHIORI, I. L. de M.; MELO, J. J.; MELO, W. J. Avaliação docente em relação às novas tecnologias para a didática e atenção no ensino superior. Avaliação, Campinas, v.16, n. 2, 2011.

MCLUHAN, M. Os meios de comunicação como extensões do homem. 10. ed. São Paulo: Cultrix, 1995.

MOLIN, S. L. E RAABE, A. Novas tecnologias na educação: transformações da prática pedagógica no discurso do professor. Acta Scientiarum.Education, Maringá, v. 34, n. 2, p. 249-259, 2012.

MOURA, E.; BRANDÃO, E. O uso das tecnologias digitais na modificação da prática educativa escolar. Revista Científica Fazer, Erechim, n. 129, p.1-17, 2013.

NOTO, C. de S. Vontade de verdade em Foucault. Philósophos, Goiânia, v.15, n. 2, p. 11-28, 2010.

OLIVEIRA, R. G. de. Tecnologias digitais de informação e comunicação (TDIC) em educação escolar: um diagnóstico a partir da formação inicial de professores de matemática. Nucleus, Ituverava, v. 9, n. 2, p. 351-361, 2012. <http://dx.doi.org/10.3738/1982.2278.752>

PÊCHEUX, M. Análise Automática do Discurso (AAD-69). In: GADET. F.; HAK, T. (Org.). Por uma análise automática do discurso: uma introdução à obra de Michel Pêcheux. Tradução de Bethânia 
Mariani et al. Campinas, SP: Unicamp, 1990a. p. 61-161. Edição original: 1969.

. A Análise do Discurso: três épocas (1983). In: GADET. F.; HAK, T. (Org.). Por uma análise automática do discurso: uma introdução à obra de Michel Pêcheux. Tradução de Bethânia Mariani et al. Campinas, SP: Unicamp, 1990b. p. 61-161. Edição original: 1969.

- Semântica e discurso: uma crítica à afirmação do óbvio. Tradução de Eni P. Orlandi et al., 2. ed. Campinas, SP: Editora da Unicamp, 1995. 1978.

PETERS, M. Governamentalidade neoliberal e educação. In: SILVA, T. T. da (Org.) O sujeito da educação: estudos foucaultianos. São Paulo: Vozes, 2010. p. 221-224.

PINTO, A. M. As novas tecnologias e a educação. In: ANPED SUL, 6, 2004, UFSM, Santa Maria, Anais... 2004. p. 1-7. Disponível em: $<$ http://www.portalanpedsul.com.br/admin/uploads/2004/Poster/Poster/0 4_53_48_AS_NOVAS_TECNOLOGIAS_E_A_EDUCACAO.pdf $>$. Acesso em: 17 fev. 2015.

PONCHIROLLI, O. O capital humano como elemento estratégico na economia da sociedade do conhecimento sob a perspectiva da teoria do agir comunicativo. Revista da FAE, Curitiba, v. 5, n. 1, p. 31-42, 2002.

QUARTIERO, E. M. As tecnologias da informação e comunicação e a educação. Revista brasileira de informática na educação. Florianópolis, n. 4, p. 69-74, 1999. Disponível em: <http://www.brie.org/pub/index.php/rbie/article/view/2294/2056>. Acesso em: 17 fev. 2015.

RAMOS, C. Excelência na educação: a escola de qualidade total. Rio de Janeiro: Qualitymark, 1992.

REICH, R. B. O trabalho das nações. Lisboa: Quetzal Editores, 1993.

ROJO, R. Pedagogia dos multiletramentos. In: __; MOURA, E. (Org.). Multiletramentos na escola. São Paulo: Parábola, 2012. p. 1131.

SILVA, G. R. Formação do escritor e a utilização de novas tecnologias: 
uma questão de modernidade e sustentabilidade. Revista do curso de Letras da UNIABEU, Nilópolis, v. 2, n. 5, p. 35-44, 2011.

SILVA, T. T. da. A produção social da identidade e da diferença. In: - (Org.) Identidade e diferença: a perspectiva dos Estudos Culturais. 9. ed. São Paulo: Vozes, 2009. p. 73-102.

SOARES-LEITE. W. S.; NASCIMENTO-RIBEIRO, C. A. do. A inclusão das TICs na educação brasileira: problemas e desafios. Magis, Revista Internacional de Investigación en Educación, v. 5, n. 10, p. 137187, 2012.

TOFFLER, A.; TOFFLER, H. Criando uma nova civilização: a política da Terceira Onda. 4. ed., Rio de Janeiro, São Paulo: Record, 1994.

UNESCO. BRASIL. Computador na escola - a dura realidade nas escolas. TICs nas Escolas, Brasília, DF, v. 3, n. 1, 2008a.

. BRASIL. Computador na escola - tecnologia e aprendizagem. TICs nas Escolas, Brasília, DF, v. 3, n. 3, 2008b.

VARGAS, M. (Org.) História da técnica e da tecnologia no Brasil. São Paulo: Editora da Unesp, 1994.

VEIGA-NETO, A. Foucault \& a educação. 2. ed. Belo Horizonte: Autêntica, 2007. Edição original: 2003.

VIEIRA, M. M. Educação e Novas Tecnologias: o papel do professor nesse cenário de inovações. Revista Espaço Acadêmico, Maringá, n. 129, p. 95-102, 2012.

WOODWARD, K. Identidade e diferença: uma introdução teórica e conceitual. In: SILVA, T. T. da. (Org.) Identidade e diferença: a perspectiva dos Estudos Culturais. 9. ed. São Paulo: Vozes, 2009. p. 772.

ZUFFO, J. A. O futuro da engenharia e o engenheiro do futuro. São Paulo: USP, Fundação Vanzolini, FINEP, 1996. (Série Engenheiro 2001) ZUIN, V. G.; ZUIN, A. A. S. Professores, tecnologias digitais e distração concentrada. Educar em revista, Curitiba, n. 42, p. 213-228, 2011. 

